\title{
ACESSIBILIDADE NO CENTRO HISTÓRICO DE LARANJEIRAS-SE: DO DIREITO À AÇÃO
}

\author{
LIMA, ERYANE VIEIRA (1);
}

SANTANA, KALYANA LORDELO DE (2);

NUNES, LAÍS SÍNTIQUE PEDROZA OLIVEIRA (3);

CAMPOS, NEIVA CARLA LESSA (4);

SANTOS, TAINÁ GOMES DOS (5)

\section{SILVA, LARISSA SCARANO PEREIRA MATOS DA (6)}

(1) Universidade Federal de Sergipe, Graduanda

e-mail:eryanevieira@yahoo.com.br

(2) Universidade Federal de Sergipe, Graduanda

e-mail: kaly.lordelo@gmail.com

(3) Universidade Federal de Sergipe, Graduanda

e-mail: laissintiquee@gmail.com

(4) Universidade Federal de Sergipe, Graduanda

e-mail:camposnc13@gmail.com

(5) Universidade Federal de Sergipe, Graduanda

e-mail: tainar0812@gmail.com

(6) Universidade Federal da Bahia, Doutoranda

Universidade Federal de Sergipe, Docente

e-mail: larissascarano@hotmail.com

\section{RESUMO}

\begin{abstract}
Sabe-se que os espaços públicos precisam ser acessíveis para a população usufruir e apreciar os bens culturais, entretanto esta não é a realidade encontrada em muitas cidades brasileiras. Neste sentido, o presente artigo aborda o tema de acessibilidade na cidade de Laranjeiras-SE, considerada patrimônio histórico e tombada pelo IPHAN, e apresenta os resultados de uma intervenção realizada pelos estudantes e pela população do munícipio. A experiência teve como objetivo identificar as deficiências existentes, alertar a população sobre o problema e junto, com a mesma, estabelecer um projeto de ação para facilitar o acesso e direito à cidade por todos.
\end{abstract}

Palavras-chave: Acessibilidade; patrimônio histórico; inclusão; espaços públicos.

\begin{abstract}
It is known that public spaces need to be accessible to the population to enjoy and appreciate cultural assets, but this is not the reality found in many Brazilian cities. In this sense, the present article approaches the theme of accessibility in the city of Laranjeiras-SE, considered historical heritage and registered by IPHAN, and presents the results of an intervention carried out between students and the population of the municipality. The objective of the experiment was to identify the existing deficiencies, to alert the population about the problem and, together with it, to establish a project of action to facilitate the access and right of all to the city.
\end{abstract}

Keywords: Accessibility; historical patrimony; inclusion; public spaces 


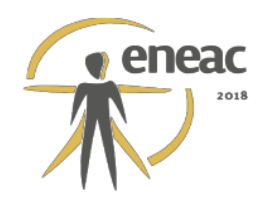

\section{INTRODUÇÃO}

O debate sobre Mobilidade Urbana, que já se estende há algum tempo, vai além da discussão sobre modais de transportes. Ele abrange também a esfera da escala humana, mostrando como a acessibilidade universal é de fundamental importância para se construir cidades melhores no que tange à qualidade de vida. Com base nisso, Jan Gehl, em seu livro "Cidade para pessoas" (2015) afirma que a cidade deve ser pensada ao nível dos olhos, levando em consideração a "dimensão humana".

Ainda em seu livro, o autor fala que durante todo o processo de desenvolvimento a cidade foi perdendo essa noção da dimensão humana para a realização de projetos arquitetônicos e urbanos, trazendo questionamentos sobre a função da escala no processo projetual. Para o autor, a cidade deve ser considerada como um local de encontro e convívio, e pensar a cidade para o pedestre é desenvolver cidades vivas, seguras, sustentáveis e saudáveis. Incluir a dimensão humana é melhorar a qualidade de vida urbana (GEHL, 2015).

Acessibilidade diz respeito a qualidade do que é acessível, ou seja, é aquilo que é atingível, que tem acesso fácil. Quando se trata de acessibilidade para pessoas com mobilidade reduzida, estas devem possuir o direito de ir e vir sem que a cidade se torne um obstáculo para as mesmas. Esse é um tema constantemente discutido no campo da arquitetura e urbanismo, o qual tem como preocupação a utilização com segurança e autonomia, total ou assistida, dos espaços públicos ou coletivos por todos.

No Brasil, essas discussões começaram com a instauração da Assembleia Nacional Constituinte de 1987 e se tornaram mais frequentes com o Estatuto da Cidade (BRASIL, 2001). Em seu Art. 2o fica determinado que "A política urbana tem por objetivo ordenar o pleno desenvolvimento das funções sociais da cidade", corroborando assim com o caput do Art. 182 da Constituição Federal de 1988, onde se determina que as políticas de desenvolvimento urbano executadas pelos poderes públicos municipais deverão "ordenar o pleno desenvolvimento das funções sociais da cidade e garantir o bem-estar de seus habitantes".

Além disso, no ano de 2012 foi criada a Lei $n^{\circ}$ 12.587, que em seu Art. $2^{\circ}$ diz que "A Política Nacional de Mobilidade Urbana tem por objetivo contribuir para o acesso universal à cidade, o fomento e a concretização das condições que contribuam para a efetivação dos princípios, objetivos e diretrizes da política de desenvolvimento urbano, por meio do planejamento e da gestão democrática do Sistema Nacional de Mobilidade Urbana" (POLÍTICA NACIONAL DE MOBILIDADE URBANA, 2012). Essa lei atualmente é utilizada como diretriz para 0 desenvolvimento dos planos de mobilidade urbana no Brasil que, em sua maioria, buscam a construção de uma cidade voltada para todos, independente da idade ou condição física. 


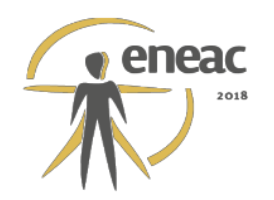

Com o objetivo de democratizar o acesso à educação de ensino superior, a Universidade Federal de Sergipe (UFS) adotou a política de cotas sociais a partir do processo seletivo 2010 ao instituir uma vaga destinada a candidatos com deficiência em cada curso presencial. Porém, há controvérsias quanto a esse avanço, haja vista que o campus da cidade de Laranjeiras-SE, sede do curso de Arquitetura e Urbanismo, por exemplo, dispõe de uma vaga para pessoas com deficiência ao mesmo tempo em que se configura como um obstáculo para 0 acesso e uso dessas pessoas. Tal dificuldade também se estende por toda a cidade. $E$ sendo o município de Laranjeiras, cerca de 20 quilômetros da cidade de Aracaju, possuidor de grande caráter histórico, tendo a maioria das suas construções tombadas pelo IPHAN desde 1996, isso se enquadra como sendo uma grande problemática, motivo de debates e discussões.

\section{Laranjeiras - SE}

A cidade de Laranjeiras surge no contexto histórico e social da produção açucareira no Nordeste, no século XIX, possuindo mais de 70 engenhos de açúcar no auge de tal produção (SANTOS, 2000). Os locais para armazenamento desta vasta produção eram denominados trapiches, edificações essas que estavam diretamente ligadas aos engenhos de açúcar da região e se localizavam próximos a rios e mares com o objetivo de facilitar o comércio. Além dos trapiches, inúmeras outras edificações foram construídas neste período de apogeu da cidade de Laranjeiras, muitas das quais não estão ligadas diretamente aos engenhos, mas sim para fins de lazer ou religioso, como teatros, praças e igrejas, a cidade chegou a receber o título de "Atenas Sergipana".

Posterior ao longo período de apogeu cultural e econômico devido à produção do açúcar credita-se a decadência de Laranjeiras (1904 a 1942) à proximidade com a capital (Aracaju) e o respectivo êxodo da população para este centro e outros mais populosos. Logo, a produção açucareira decai, por consequência muitos dos edifícios da cidade perdem suas funções originais, e todo o centro histórico sofre uma série de degradações, em especial os trapiches (OLIVEIRA, apud NOGUEIRA E SILVA, 2012, pg. 16).

A elevação do conjunto urbano que compreende as construções civis e igrejas de Laranjeiras à categoria de Monumento Histórico Estadual pelo Decreto 2.048 de 12 de março de 1971 irá fomentar o início de um "Despertar do Conhecimento", em que se coloca em destaque a trajetória de importância cultural, social, econômica e acadêmica que sempre estiveram presentes nesta cidade para a sociedade. Logo, em busca de se construir um local capaz de agregar os valores materiais e imateriais, o IPHAN e o Programa Monumenta do ano de 2004, idealizado pelo Ministério da Cultura, viu a possibilidade de se implantar um Campus da Universidade Federal de Sergipe na cidade de Laranjeiras (NOGUEIRA e SILVA, 2012).

O campus da Universidade Federal de Sergipe foi instalado no conjunto arquitetônico conhecido como "Quarteirão dos Trapiches", formado pelas seguintes ruínas: "Trapiche Santo Antônio", Sobrado 117, Antiga Exatoria, Casarão 159 e Ruínas ao lado do Mercado municipal da cidade. Foi implantado inicialmente com o intuito de abrigar 5 cursos, dentre eles o curso de Arquitetura e Urbanismo, área essa cuja função primordial é a criação de espaços adequados, quanto à acessibilidade, economia, segurança, e conforto, às várias atividades humanas. Entretanto, mesmo com a implantação do campus e com a possibilidade de uma parceria entre a comunidade e a universidade, Laranjeiras ainda apresenta muitos problemas que dificultam viver sua história e cultura. 


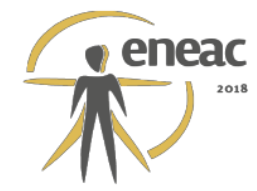

"Para o Iphan, a acessibilidade deve proporcionar um deslocamento fácil e seguro para todos os usuários. As áreas consagradas como patrimônio cultural devem se constituir em espaços onde é possível conhecer, usufruir e desfrutar do patrimônio cultural. Os centros históricos devem possibilitar o usufruto do espaço público e do patrimônio, garantindo o direito constitucional à cidade e à cultura." (IPHAN, 2014)

Partindo então desse princípio, tem-se uma realidade oposta à regra. Choay (1999, p.11) cita que o patrimônio cultural é "constituído pela acumulação contínua de objetos que congregam sua presença comum ao passado: são obras e obras primas das belas artes e das artes aplicadas, trabalhos e produtos de todos os saberes e conhecimentos humanos". Por outro lado, apesar de ser considerado como tal e, por esta razão, deve garantir o acesso de todos, nota-se que sua configuração é excludente para boa parte da população.

Essa contradição direcionou o estudo ao município de Laranjeiras e ao tema da acessibilidade em patrimônios de caráter público. Para tanto, foi estabelecido um perímetro que engloba bens de valor cultural com caráter de exemplificação, abrangendo o tema para todo o município, porém com foco em determinadas edificações (Imagem 1).

\section{Imagem 01: Perímetro de estudo em destaque.}

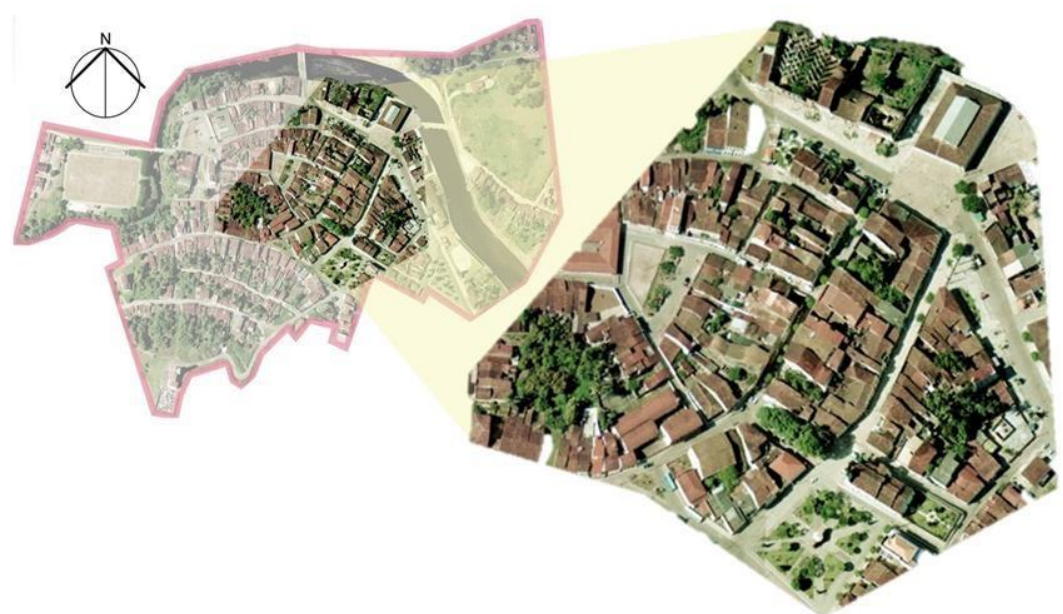

Fonte: Elaborado pelas autoras, 2017

Após detectar o problema não pode-se pensar em Laranjeiras sob uma visão técnica e autoritária. Que o problema existe é um fato, mas o objetivo não é impor soluções prontas, e sim partir de experimentações. Questiona-se: como a população de Laranjeiras vê esse problema? A partir desse diagnóstico, tendo em vista o tema "Acessibilidade no centro histórico de Laranjeiras-SE", o objetivo foi alertar a população do município para o problema e construir, juntamente com os alunos do Campus da Universidade Federal de Sergipe, uma discussão acerca do assunto. Somente a partir das experimentações delineadas nesse estudo é que será possível estabelecer um projeto de ação que tem como interesse despertar e facilitar o acesso e direito de todos à cidade.

\section{METODOLOGIA}

O primeiro passo da pesquisa foi o estudo do tema Mobilidade Urbana e Acessibilidade Universal. Após a leitura do material teórico, foi realizada uma verificação in loco, onde foram observados e registrados através de fotografias os principais acessos a cada uma das edificações escolhidas. Ainda durante a visita, questões como a qualidade dos passeios, calçadas e rampas, bem como a iluminação em horários noturnos também foram observados. Em seguida, deu-se início a comparação dos dados coletados durante a visita 


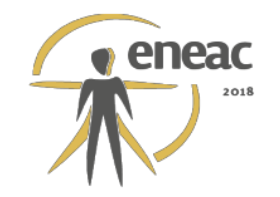

com as recomendações da NBR 9050 (ABNT, 2015) que trata da acessibilidade em espaços e equipamentos públicos. Dessa forma, foi possível identificar quais os maiores problemas enfrentados pela população com mobilidade reduzida, e como as mesmas são expostas a situações cotidianas no município de Laranjeiras - SE.

Anteriormente à visita de campo, foi feita a delimitação de um perímetro de estudo que incluiu a Universidade Federal de Sergipe, Mercado Municipal, Bureau de Informações Turísticas, Terminal Rodoviário, Museu de Arte Sacra, Igreja Sagrado Coração de Jesus, Praça da Matriz, Igreja Presbiteriana, Museu Afro-brasileiro de Sergipe, Câmara Municipal, Entrada da Travessa Prof. Oliveira, Casa de Cultura João Ribeiro e início do Calçadão Getúlio Vargas. Nesse perímetro inicial de estudo foram pontuados alguns dos bens culturais de domínio público que necessitam de melhorias no tocante à acessibilidade.

Imagem 02: Percurso da visita de campo.

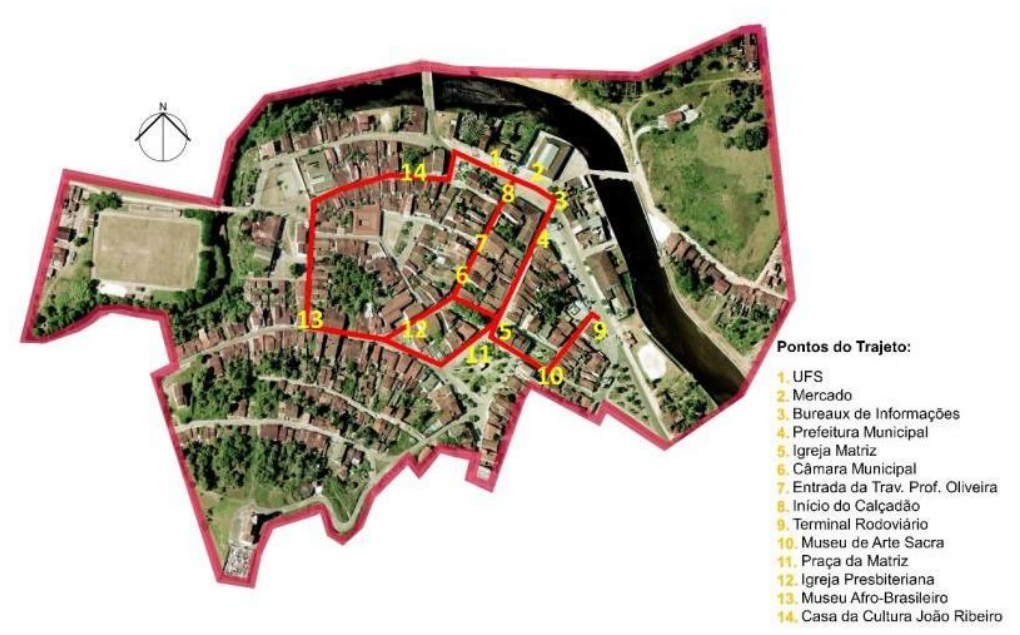

Fonte: Elaborado pelas autoras, 2017

Posteriormente a isso, foi traçado uma nova rota, também circunscrita por edifícios culturais de Laranjeiras, por onde foi realizada a caminhada. Foi levada em consideração a delimitação de um perímetro que concentrasse uma área de grande fluxo de pessoas, que pudesse ser iniciada e finalizada em um determinado período do dia, e que levasse em conta a exposição e limitação das crianças participantes.

A ação coletiva contou com a participação de docentes e de uma discente do Campus Laranjeiras conjuntamente com alunos, de 8 a 14 anos, de uma escola estadual do próprio município. Foi delineado um trajeto por onde todos foram convidados a percorrer portando muletas, carrinho de bebê, mala de viagem, vendas, e/ou fazendo uso de cadeira de rodas. $\mathrm{O}$ objetivo foi o de direcionar o olhar da população para o que estava acontecendo, ou seja, para as dificuldades que aqueles com mobilidade reduzida sofrem diariamente ao se deslocar pela cidade de Laranjeiras. Também foram recolhidas assinaturas para submeter um abaixo assinado ao órgão responsável por regulamentar tal situação, no caso, o IPHAN.

\section{ANÁLISE DO ESTUDO DE CASO}

\subsection{VISITA IN LOCO}

Após a visita em campo foram feitos registro para mostrar como é na prática e como deveria ser seguindo as orientações da NBR 9050 (ABNT, 2015), sendo esta a norma mais utilizada por arquitetos e engenheiros, pois estabelece critérios e parâmetros técnicos a serem observados quanto ao projeto, construção, instalação e adaptação do meio urbano e rural, e de edificações às condições de acessibilidade. 


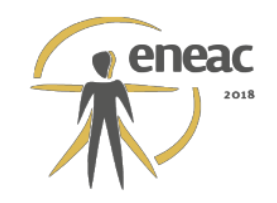

Pode-se observar nas imagens abaixo as irregularidades da cidade de Laranjeiras como: a faixa livre da calçada depois da rampa não foi respeitada o mínimo de $1,20 \mathrm{~m}$, falta de piso tátil, inexistência de uma sinalização da rampa ou da travessia, utilização de pedras irregulares para a pavimentação dificulta ainda mais o deslocamento, o acesso a alguns edifícios públicos não possibilite a entrada de forma independente, nas rampas encontradas não é respeitada a inclinação recomendada pela norma que é de $8,33 \%$, a inexistência de corrimões em rampas que são utilizados como apoios, o material utilizado deveria ser regular, firme, estável e antiderrapante, nas escadarias a inexistência de piso tátil de alerta e por fim para se localizar na cidade existem placas mas pelo seu tamanho a leitura é dificultada comprometendo assim a orientação. Isso mostra como a cidade não possui as condições mínimas para o deslocamento de pessoas com a mobilidade reduzida. As fotos abaixo mostram a realidade da cidade.

\section{Imagem 03: Fotografia da calçada e rampa com dimensões inadequadas}

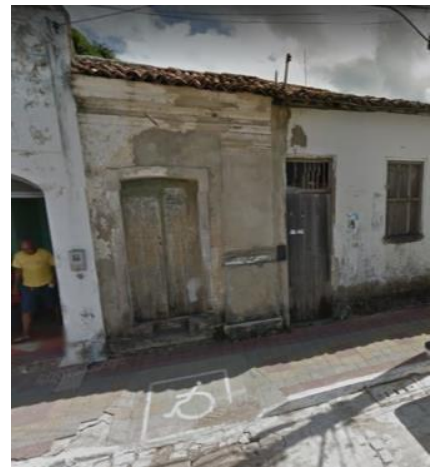

Fonte: Foto tirada pelas autoras in loco, 2017.

Imagem 04: Travessia não sinalizada e com pavimentação inadequada entre o Centro de Tradições e o Bureaux de Informações Turísticas, Laranjeiras- SE.

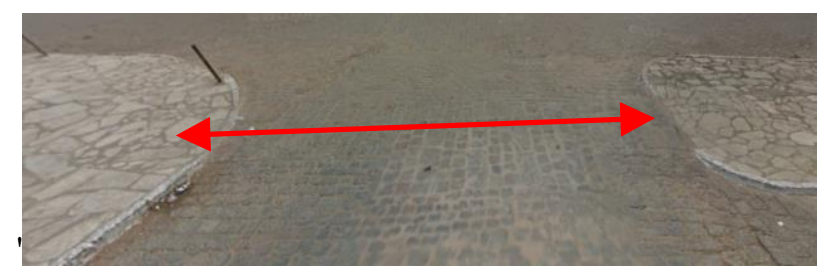

Fonte: Foto tirada pelas autoras in loco, 2017. 


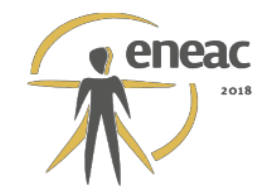

Imagem 05: A inexistência de rampas para acessar o edifício da Universidade Federal de Sergipe, que comporta o curso de Arquitetura e Urbanismo, Laranjeiras- SE.

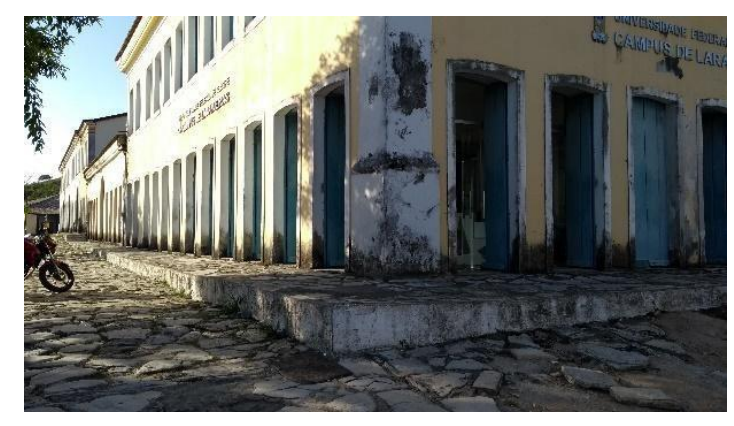

Fonte: Foto tirada pelas autoras in loco, 2017.

Imagem 06: A inexistência de rampas para acessar o edifício da Biblioteca, Laranjeiras- SE.

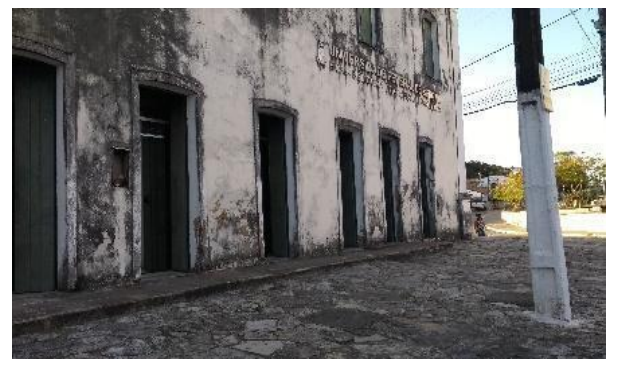

Fonte: Foto tirada pelas autoras in loco, 2017

Imagem 07 e 08: Qualidade das rampas de acesso ao calçadão de Laranjeiras- SE.
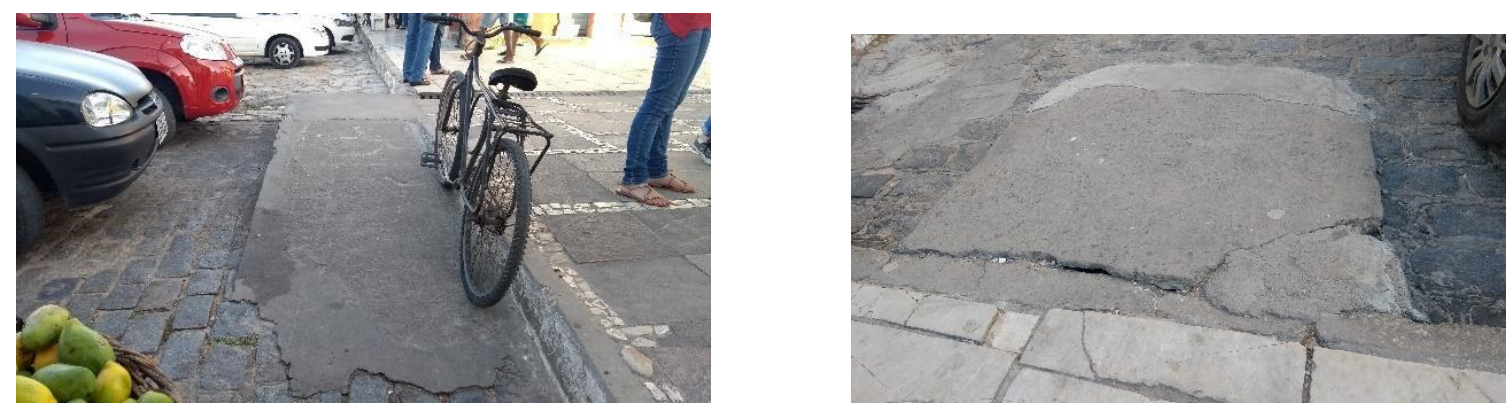

Fonte: Foto tirada pelas autoras in loco, 2017. 


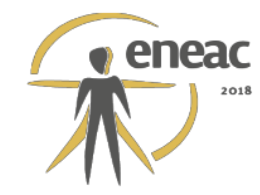

Imagem 09: Rampa de acesso a Rodoviária de Laranjeiras- SE com inclinação maior do que a permitida, além da falta de corrimão.

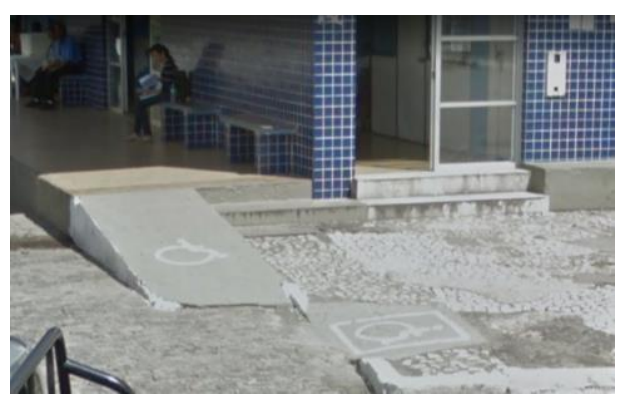

Fonte: Foto tirada pelas autoras in loco, 2017.

Imagem 10: Rampa de acesso a Igreja Matriz Sagrado Coração de Jesus, Laranjeiras SE com inclinação maior do que a permitida.

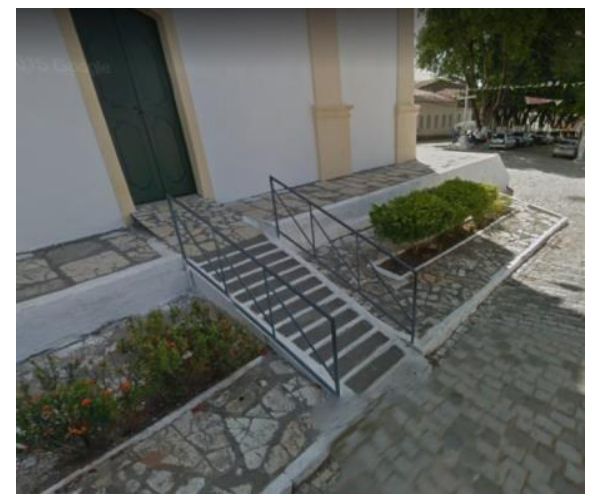

Fonte: Foto tirada pelas autoras in loco, 2017.

Imagem 11: Placas informativas no "Mercadinho Mota" localizado entre a Praça São Oliveira e Rua Sagrado Coração de Jesus, Laranjeiras SE.

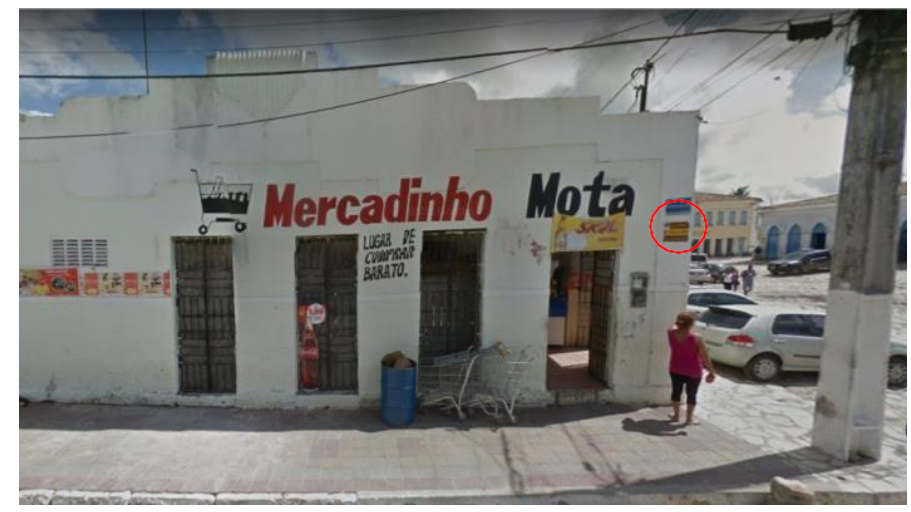

Fonte: Foto tirada pelas autoras in loco, 2017. 


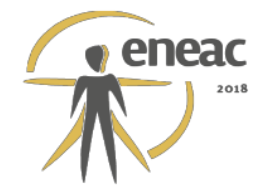

\subsection{INTERVENÇÃO}

Em janeiro de 2018 foi realizada uma vivência na cidade de Laranjeiras - SE, como o objetivo de passar por um processo de sensibilização podendo conscientizar a população no sentido de eliminar barreiras atitudinais (barracas e motos nas calçadas, carro na frente da rampa ou na faixa de travessia, etc.), esses que dificultam o acesso à cidade para aqueles que possuem mobilidade reduzida infringindo a Lei Federal $\mathrm{n}^{-1}$ 10.257/2001 conhecida como "Estatuto da Cidade", que é uma garantia que todo brasileiro tem de usufruir da estrutura e dos espaços públicos de sua cidade, com igualdade de utilização.

Sendo assim, além dos alunos e professores da Universidade Federal de Sergipe (UFS) também foram convidadas crianças da escolha pública Cônego com idade entre 7 e 10 anos, foi escolhido essa faixa etária por ser nesse momento que ocorre as maiores mudanças físicas e psicológicas começando a discernir o certo do errado e passa a compreender mais a sociedade, ordens sociais e grupos o que torna esta faixa etária uma área instável de desenvolvimento psicológico.

Com isso, foi marcado o ponto de encontro na Universidade Federal de Sergipe na qual foi mostrado a todos o trajeto que as pessoas iam realizar utilizando cadeiras de rodas, muletas, vendas, bengalas, carrinho de bebê e malas de viagem para assim simular tanto as deficiências motoras e visuais, como situações de locomoção diária.

A caminhada acompanhada começou da UFS seguindo em direção a Igreja Matriz Sagrado Coração de Jesus passando pela prefeitura municipal. Durante todo o percurso, os alunos conversaram com a população e recolheram assinaturas para compor o abaixo assinado que tem como objetivo ser levado aos órgãos das diferentes instâncias responsáveis pelo centro histórico de Laranjeiras, incluindo prefeitura municipal, governo do estado de Sergipe e IPHAN como uma forma de mostrar o descontentamento com a cidade.

\section{Imagem 12: Percurso da intervenção.}

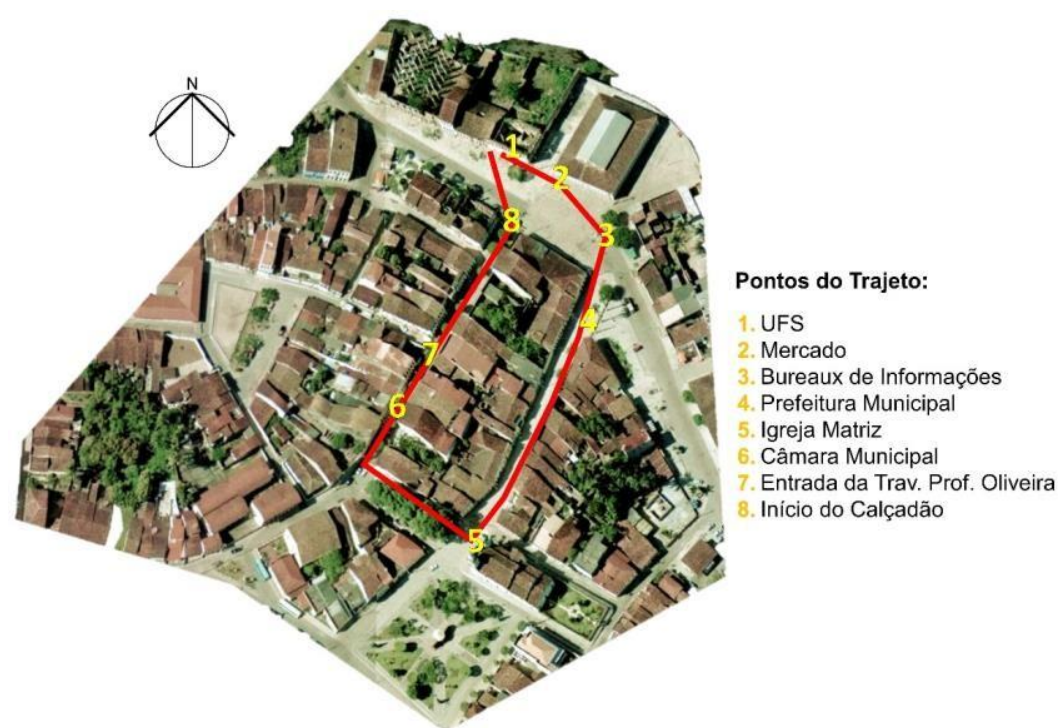

Fonte: Elaborado pelas autoras, 2017 
Ao longo da vivência foram observadas dificuldades provocadas pela quantidade buracos nas calçadas, pela pequena dimensão da mesma, a existência de pedras desniveladas dificultava a passagem do carrinho do bebê e da cadeira de rodas, alguns participantes tentaram acessar edifícios, mas sem sucesso pela falta de rampas ou pela grande inclinação dela. Além dos problemas arquitetônicos existem barreiras criadas pela própria população no momento em que locava as barracas de venda nas calçadas interrompendo o percurso, obrigando o pedestre a desviar ou passar pela rua, disputando espaço com os transportes motorizados, carros estacionados obstruindo rampas, calçadas, faixa de pedestre, a fim de alertar a população e conscientizá-la, foi feito um desafio com as crianças em que elas tinham que identificar essas situações e aplicar uma multa educativa além de colocar band-aids nas falhas encontradas.

Logo após as atividades externas, os participantes retornaram para a Universidade para discutir sobre a experiência. Foi consenso entre os participantes que a cidade de Laranjeiras não oferece a infraestrutura necessária para a circulação independente de pessoas com deficiência ou mobilidade reduzida.

Imagem 13: Multas e band-aids que foram utilizados na intervenção.
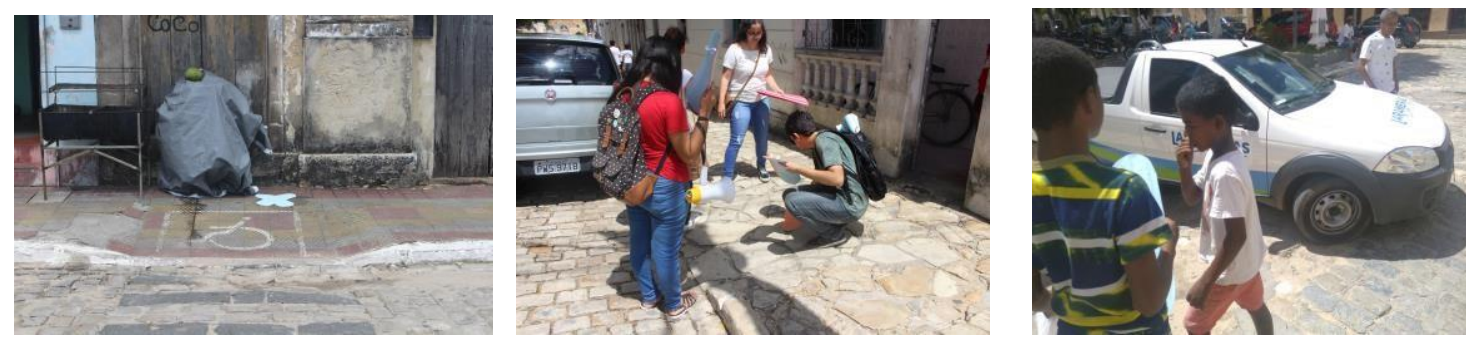

Fonte: Foto tirada pelas autoras in loco, 2018.

\section{CONSIDERAÇÕES}

A Vivência em Acessibilidade com a participação da população foi pensada como forma de expor as problemáticas que envolvem a cidade de Laranjeiras no que diz respeito à acessibilidade de pessoas com mobilidade reduzida em vivenciar a cidade e a cultura, com enfoque nos edifícios culturais que em sua maioria são considerados patrimônios culturais pelo IPHAN. Além disso, foi um meio encontrado de melhorar a comunicação entre a universidade e a comunidade local, permitindo-a vivenciar as dificuldades enfrentadas pelos portadores de deficiência física e refletirem quanto as mudanças que deveriam ser realizadas.

Laranjeiras já foi objeto de estudo de outras pesquisas nos diversos cursos, contudo a maioria desses resultados não é colocada em prática e são desconhecidos pela população, que na maioria das vezes não participam no desenvolvimento dos mesmos.

Os cursos inseridos no campus de Laranjeiras na sua fundação, além de Arquitetura e Urbanismo, foram Arqueologia, Museologia, Teatro e Dança com o objetivo de utilizar a cidade e sua história como objeto de estudo e assim usar os conhecimentos científicos como forma de contribuir na conservação seja dos conjuntos arquitetônicos como da cultura. Porém, infelizmente estes estudos não se convertem em benefícios práticos para a comunidade, mostrando que essa comunicação entre a cidade e a Universidade prevista quando foram inseridos os cursos é muitas vezes inexistente. A uma exceção dizia respeito ao curso de Dança que, esporadicamente, dava aulas para as crianças da cidade. 


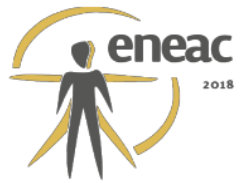

No tocante à vivência que foi realizada, pode-se afirmar que ela foi importante não só para as pessoas que estavam envolvidas na ação, pois estas puderam sentir a real necessidade da adaptação dos espaços públicos para todos os cidadãos, bem como também foi importante para aqueles que estavam somente de passagem e que observavam de longe o que estava acontecendo, refletindo sobre o ocorrido.

Durante a vivência, a relação cidadão/cidade foi vivida de maneira mais intensa, isso porque as pessoas puderam observar mais cada detalhe existente nas ruas e perceber pequenos problemas que durante uma caminhada normal não seria possível. Com a ajuda de todos, conseguiu-se pontuar os pontos mais críticos do trajeto escolhido e identificar pequenas soluções para tais problemas.

Com a conclusão desta ação se espera que pequenas mudanças de hábitos sejam feitas na vida daqueles que participaram da mesma, bem como ser possível chamar atenção da prefeitura da cidade ao problema que é a falta de acessibilidade em Laranjeiras.

\section{REFERÊNCIAS}

ASSOCIAÇÃO BRASILEIRA DE NORMAS TÉCNICAS, NBR 9050: Acessibilidade a edificações, mobiliários, espaços e equipamentos urbanos. Rio de Janeiro: ABNT, 2015

COSTA, P. L. [et al.]; Avaliação ergonômica de um ambiente construído em uma repartição pública. In: MONT'ALVÃO, C.; VILLAROUCO, V. (Orgs.) Um novo olhar para o projeto: a ergonomia no ambiente construído. Teresópolis, RJ: 2AB, 2011. 184p.

CHOAY, Françoise. Alegoria do Patrimônio. Lisboa: edições 70,1999.

DUARTE, C. R. S.; COHEN, R. Acessibilidade como fator da construção do lugar. In: PRADO, A. R. A.; LOPES, M. E.; ORNSTEIN, S. W. (Orgs.) Desenho Universal: Caminhos da Acessibilidade no Brasil. São Paulo: Annablume, 2010. 306p.

ELALI, G. A.; DINIZ, J. P. G. D. A gradação da acessibilidade física como elemento de orientação e segurança psicológica. In: COSTA, A. D. L.; ARAÚJO, M.C. A (Orgs.) Acessibilidade no Ambiente Construído: Questões Contemporâneas. João pessoa, PB: IFPB, 2013. 213p

GEHL, Jan. Cidades Para Pessoas. São Paulo: Editora Perspectiva, 2015.

Manual de Acessibilidade em Centros Históricos. Disponível em: <http://portal.iphan.gov.br/notícias/detalhes/65/>. Acesso em: 27 nov. 2014.)

Política Nacional de Mobilidade Urbana - Lei oㅜ 12.587/2012, de 19 de ago de 2013. O Pacto Social pela Mobilidade Urbana. Porto Alegre, 2013.

PREFEITURA MUNICIPAL DE LARANJEIRAS, SECRETARIA MUNICIPAL DE EDUCAÇÃO, CULTURA E LAZER - SEMEC - MINISTÉRIO DA EDUCAÇÃO E DO

DESPORTO E LAZER. Laranjeiras: Sua história, sua cultura, sua gente. Laranjeiras, 2000.

RABELO, Agnes. Panorama mundial das redes sociais: 91 estatísticas que você precisa saber. Disponível em:<https://inteligencia.rockcontent.com/estatisticas-de-redes- sociais/>. Acesso em: 05 dez. 2017.

Secretaria Nacional da Mobilidade Urbana SeMob / Ministério das Cidades. Caderno 


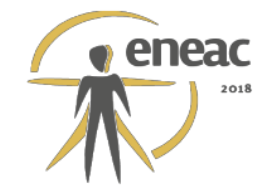

Técnico para Projetos de Mobilidade Urbana Transporte Ativo, 2016.

SILVA, Eder Donizeti da; NOGUEIRA, Adriana Dantas.(Org.) A Cidade, o Trapiche e a Universidade. 1. Ed. São Cristóvão: Universidade Federal de Sergipe, 2012. 